\title{
Types of Blended Learning
}

\author{
N. V. Moiseienko, I. I. Ozarko \\ Ivano-Frankivsk National Technical University of Oil and Gas, Ukraine \\ Corresponding author. E-mail: zipex93@gmail.com
}

Paper received 27.01.19; Accepted for publication 08.02.19.

\section{https://doi.org/10.31174/SEND-PP2019-187VII76-11}

Abstract. Different types of blended learning are described in the article. Blended learning is different from traditional approach where teachers give the lecture first followed by exercises in the classroom. The comparison between different types of blended learning is shown. Blended learning is a teaching method that combines traditional face-to-face instruction with technology. Blended learning models extend the reach of the instruction beyond the classroom through the use of digital resources.

Keywords: blended learning, station rotation, lab rotation, flipped classroom, individual rotation, flex model.

Over the last years education innovators around the country continued to pursue expanded definitions of student success, personalized approaches, and wholly new models of school. The ability to create personalized instruction and deliver it via modern technology makes the rotation model an especially wise choice for students in the $21 \mathrm{st}$ century. The rotation model, however, is an engaging method that keeps students entertained and informed much more effectively than a traditional classroom. Rather than choosing a single approach and rigidly sticking to it, teachers can introduce students to a variety of stations that are sure to keep students on their toes. The program helps to keep both students and teachers focused and encourages the development of valuable timemanagement skills. Not only students are being exposed to a diverse learning strategy, but also the flexibility and customization of the rotation model makes the learning process much more enjoyable and engaging. The rotation model is an innovative teaching strategy that offers improved flexibility and customization. The program is advantageous for both students and instructors. Using the rotation model in classroom is a productive and enjoyable teaching strategy that is advantageous for both students and teachers. One of the primary benefits of this system is that it can be used by anyone. The rotation model can be used for students of all ages in any academic subject. It is not restricted by any major limitations. Rotation model is a course or subject in which students rotate on a fixed schedule or at the teacher's discretion between learning modalities, at least one of which is online learning. Other modalities might include activities such as small-group or full-class instruction, group projects, individual tutoring, and pencil-and-paper assignments. The students learn mostly on the brick-and-mortar campus, except for any homework assignments. This program is also available to students completing their classes remotely because using of technology makes it easy to communicate with teachers and other students. Distance learning has come a long way since the inception of the internet. The days of using snail mail and waiting days or even weeks for a response from your teacher are over; now students and teachers receive feedback practically instantaneously. Rotation models take full advantage of recent technological developments and supply educators and pupils with engaging and entertaining learning opportunities. Rotation models are particularly beneficial because they incorporate and reflect the many advantages offered by modern technology. The method provides teachers with constant infor- mation on the performance of their students and allows for quick and easy modifications in the event that a student requires assistance. Students may also enjoy having greater control over their own learning. Rather than sitting through long lectures of information they have already understood or struggling to keep up with a class that has been way ahead of them, each student can play a part in directing their experience in the classroom. Comparing online learning to a traditional classroom where students must attend class on certain days and times it can be considered less convenient, but they also get the benefit of personal attention and face-to-face interaction with others. According to "Blended: Using Disruptive Innovation to Improve Schools," by Michael Horn and Heather Staker, blended learning is a formal education program 1) delivered at least in part through digital learning, with some flexibility for students to choose the way they want to learn, 2) at least partly in combination with a physical classroom and teacher and 3) with opportunities for students to learn through activities that capitalize on different learning modalities.

Blended learning is a formal education program in which a student learns, at least in part, through online learning with some element of student control over time, place, path, and/or pace and at least in part, at a supervised brick and-mortar location away from home. The modalities along a student's learning path are connected to provide an integrated learning experience, which may mean using data from online learning to inform and drive a student's offline learning (Horn and Staker, 2015). Blended learning emerged from a disruptive force in education: online learning. The term online learning is often synonymous with digital learning, e-learning and virtual learning. A successful disruptive innovation contains three ingredients:

1. Enabling technology is an invention or innovation that makes a product more affordable and accessible to a wider population.

2. Innovative business model is a business model that targets non-consumers (new customers who previously did not buy products or services in a given market) or low-end consumers (the least

profitable customers). This is most easily accomplished by new entrants since they are not locked into existing business models.

3. Coherent value network is a value network in which upstream and downstream suppliers, partners, distributors, and customers are each better off when the disruptive 
technology prospers. The evolution of the computer industry provides a clear example of disruptive innovation at play. Apple's earliest PCs were quite rudimentary compared to the expensive and sophisticated mainframe and minicomputers that dominated the 1960s and 70s. But Apple's original PC customers were not demanding professionals looking for powerful machines. Instead, Apple marketed the PC to non-consumers: hobbyists and children who were delighted that they could afford a contraption that they could tinker with and use for basic word processing and computing. Over time, Apple then shepherded the PC up market by improving its technology to eventually serve the needs of more and more demanding customers, offering higher processing speeds and storage volume, and pulling those customers away from mainframe and minicomputer competitors with a lower cost offering. In a similar vein, online learning stands to offer a solution that is more affordable and accessible than many traditional schools are able to offer through strictly teacher-led instruction. Online learning as a modality can also provide students with greater access and flexibility over when and how they learn than can highly centralized, teacher-led lectures that have dominated many schools for centuries. Also, like all disruptive forces, many online learning programs got their start by offering a product and service where the alternative was nothing at all. For example, in the United States, early online courseware offered advanced courses in school systems that were unable to offer those same courses face-to-face. Rather than trying to compete head-on with traditional teacher-led instruction, these courses competed with circumstances of non-consumption when students were unable to access learning, and schools were unable, due to limited resources, to offer it.

While there are many ways to apply blended learning to a curriculum, some of the most popular examples include flipped classroom models, where students learn online at home, then spend in-class time practicing with a teacher available to assist them; or rotation models, where students move between learning stations, with at least one station being a digital space where students can access a variety of learning resources. Though there are many ways to implement a blended learning program, there are a few commonalities in what works, what doesn't and what is destined for failure. The best blended learning programs seem to have some common threads. One of the biggest indicators of a successful program is intentional technology use. Whether creating digital resources and activities or planning a large purchase of student devices, the technology should support the learning, not the other way around. Mindful pairing of digital resources to learning outcomes is an excellent way to ensure that any blended learning program will produce the desired learning outcomes. This also means being mindful of students with special needs, and students without access to digital resources at home. Even the best digital tool is useless if it is inaccessible to learners, so schools should create supports ahead of time for those who need them.

Another indicator of a great blended learning is a teacher who is well-trained and well-supported in applying both digital and non-digital teaching practices. Much of our teacher professional development focuses on use of programs or tools, but falls short when it comes to impart- ing best practices around teaching and learning methods, digital and in-person instruction, differentiated assessment and data analysis. The best programs feature teachers who are strong in all these areas. Blended learning is a teaching method that combines traditional face-to-face instruction with technology. Blended learning models extend the reach of the instruction beyond the classroom through the use of digital resources. For example, a class taught in a blended format might ask students to play an online game to reinforce learning following the introduction of a new topic in class. Another example of blended learning might require that students view an introductory video prior to the introduction of the concept in class. Blended learning is an educational model where some lessons are delivered in a traditional classroom format and some lessons are delivered in a digital one. In blended learning the traditional classroom is still in effect; though some of the lessons are replaced with online learning. Blended learning is also referred to as hybrid learning because it is a combination of the traditional classroom and educational technology. Future trends in blended learning are moving towards increasing incorporation of educational technology innovations such as mobile learning, virtual classrooms and webinars. Blended learning is thought to be more student-centered, because students can access lessons at their own place and time to reinforce what they learned in the classroom. Teachers can design lessons so that students can learn some of the content by themselves and follow up with face-to-face discussions.

There are many different types of blended learning which depend on the degree of technology implemented in instruction. Horn and Staker have categorized four particular types of rotation-based blended learning programs: station rotation, lab rotation, flipped classroom and individual rotation. Station rotation means that a student goes from station to station within a classroom or group of classrooms as they learn a subject. Stations involve different types of activities, such as small group activities, and at least one online learning station. A blended learning station could be a collaborative station. For example, if students have read an article, they can work together on a shared google doc to analyze the aims the author makes within the text. But a blended learning station could also be an independent station, where students could complete an online assessment or view a preselected TED Talk video providing background knowledge for the current unit. Stations can run from start to finish during one class period, or can run the span of several days. They do not need to happen daily. Blended learning gives the possibility to work for you and your students. It is obvious that the important part of stations is the pre-work. But the benefit of such work is a classroom full of engaged students. Having a limited amount of class time many teachers cannot always satisfy the learning needs and speeds of all students. This gives teachers a chance to provide them with different digital and nondigital activities. As a result, it can benefit classrooms filled with students who have distinct learning styles and needs. Lab rotation means that a student may have a similar experience to station rotation except that they are likely to navigate across a campus to different environment rather staying in one setting as they rotate. At least one of the labs will involve computers and online learning. 
Individual rotation model allows students to rotate through stations, but on individual schedules set by a teacher or software algorithm. Unlike other rotation models, students do not necessarily rotate to every station; they rotate only to the activities scheduled on their playlists. Individual rotation is a course or subject in which each student has an individualized playlist and does not necessarily rotate to each available station or modality. An algorithm or teacher sets individual student schedules. Flipped model flips the traditional relationship between class time and homework. Students learn at home via online coursework and lectures, and teachers use class time for teacher-guided practice or projects. Flipped model is a course or subject in which students participate in online learning off-site in place of traditional homework and then attend the brick-and-mortar school for face-toface, teacher-guided practice or projects. The primary delivery of content and instruction is online, which differentiates it from students who are merely doing homework practice online at night. This model enables teachers to use class time for more than delivering traditional lectures.

Flex model lets students move on fluid schedules among learning activities according to their needs. Flex model can be defined as:

1. A course or subject in which online learning is the backbone of student learning, even if it directs students to off-line activities at times. This gives students and teachers more control over how they use their time: teachers have time to work individually with students because they are generally no longer standing in front of a class delivering content and students can move through the lessons and materials at their own place.

2.Students move on an individually customized, fluid schedule among learning modalities. Such flexibility gives students the possibility to operate independently and to receive help from teachers when it's needed.

3.The teacher of record is on-site, and students learn mostly on the brick-and-mortar campus, except for any homework assignments.

4. The teacher of record or other adults provide faceto-face support on a flexible and adaptive as-needed basis through activities such as small-group instruction, group projects, and individual tutoring. Some implementations have substantial face-to-face support, whereas others have minimum support. Teachers provide support and instruction on a flexible, as-needed basis while students work through course curriculum and content. This model can give students a high degree of control over their learning.

Many teaches have taken the flex model of blended learning and run with it in a way that gives students a significant amount of control in terms of learning. With this student-directed option of the flex model of blended learning, most assignments are completed on-line. For example, a student begins with a list of curriculum from which to choose. He or she takes quizzes to show mastery. Extra help is provided in the form of enrichment if needed. Therefore, students work through the curriculum at their own place and can spend as much or as little time needed to master a particular concept. The studentdirected option may also include project-based learning opportunities guided by teachers. Teachers may be assigned to specific students and should serve as leaders in learning. In short, they assist when needed and encourage students to challenge themselves in learning. This studentdirected option may help to increase student completion and ongoing success in education.

Another component of blended learning is the scheduling method. The instructor decides whether he or she will use the synchronous or asynchronous method of scheduling. In synchronous learning, the teacher and the student may be meeting face to face in the classroom, or the instructor may choose a virtual venue. In the case of the latter, the interaction is still instantaneous, allowing the students to have their questions answered via chat, web conferencing, or a similar means, just as if everyone was in the actual brick and mortar classroom together.

A La Carte model enables students to take an online course with an online teacher of record in addition to other face-to-face courses, which often provides students with more flexibility over their schedules. A La Carte courses can be of such an advanced placement or elective course, making it one of the most popular models in blended high schools. A La Carte model is a course that a student takes entirely online to accompany other experiences that the student is having at a brick-and-mortar school or learning center. The teacher of record for the a la carte course is the online teacher. Students may take the a la carte course either on the brick-and mortar campus or off-site. This differs from full-time online learning because it is not a whole-school experience. Students take some courses a la carte and others face-to-face at a brickand-mortar campus. Enriched Virtual model is an alternative to full-time online school that allows students to complete the majority of coursework online at home or outside of school, but attend school for required face-toface learning sessions with a teacher. Unlike flipped, enriched virtual programs usually don't require daily school attendance; some programs may only require to be attended twice a week. Enriched Virtual model is a course or subject in which students have required face-to-face learning sessions with their teacher of record and then are free to complete their remaining coursework remote from the face-to-face teacher. Online learning is the backbone of student learning when the students are located remotely. The same person generally serves as both the online and face-to-face teacher. Many enriched virtual programs began as fulltime online schools and then developed blended programs to provide students with brick-andmortar school experiences. The enriched virtual model differs from the flipped classroom because in enriched virtual programs, students seldom meet face-to-face with their teachers every weekday. It differs from a fully online course because face-to-face learning sessions are more than optional office hours or social events; they are required.

In the past few years, blended learning has been applied in many classrooms. The goal of any learning program is to produce desired results. If a blended learning program is not improving student success, it should be discontinued. Trying to measure improvements in blended learning and evaluate the efficacy of a program one must take specific steps to develop a comprehensive evaluation program that determines effectiveness. By evaluating a program's efficacy instructors can determine what works or what doesn't work in a way that promotes accountabil- 
ity. This means that programming should include best practices that are evidence-based and research driven. Naturally, the first step in determining program efficacy is to document what lessons are being taught. In this step, a helpful strategy is to use a spreadsheet that includes lesson titles, a brief description of the content, specific benchmarks or standards the lesson meets, and the dates or the order in which the lessons should be delivered. It can be easily modified to add lessons or specific details within each lesson if it is necessary.

Blended learning has been now firmly established methodology, particularly in higher education. It is an important component of classroom teaching since it can promote effective learning. Tech-rich models may use technology as a productivity, research, or assessment tool. Blended models, on the other hand, use technology to deliver content directly to students in a manner that in turn shapes offline learning as well. Building leadership is creatively answering students' demand for technology access and school district administration in looking scalable learning models and strategies. Excellent teachers can shift from routine to flexible roles. Online and blended learning will be crucial drivers for scaling new instructional models that offer both greater access and more reliably differentiated and customized learning experiences. Digital instruction provides basic knowledge and skill development, allowing excellent teachers to spend their time with students building deeper knowledge, developing higher-order thinking skills, and reinforcing and ap- plying these skills and knowledge to solve real-world problems. Teachers can focus on enriched and personalized instruction with smaller groups of students. To implement this model students must have Internet access and individual student access to computers. Digital instruction may be purchased as discrete programs from external providers or developed by the school, such as by digitizing lessons by the most outstanding teacher on a particular topic. Software that tracks student progress and aids in identifying instructional needs is particularly important to this model. The more time students spend with digital instruction, the more important the quality of digital instruction becomes. Schools in which teachers record their own instruction need recording and playback equipment. Some of the future trends in blended learning can make education even more accessible to students and more relevant as the digital age progresses. In fact, one of the mottos of blended learning is 'Learn Anywhere - Learn Anytime' because learning materials are always available on the web and on mobile devices. The truth is that technology will never replace good teachers, who can create relationships with students and learn students' strengths and challenges. When teachers do not have appropriate and ongoing support to change their teaching style to a blended learning model, and/or support for keeping the network, devices, and programs current and in good repair, a system will not work. Perhaps the most underrated aspect of any blended learning program is the long-term support plan, for both human and digital resources.

\section{REFERENCES}

1. Ali, Mohd Fadzli; Joyes, Gordon; Ellison, Linda, Blended Learning: The Evaluation Studies: Advanced Science Letters, Volume 20, Numbers 10-12, October 2014, pp. 2193-2197.

2. Blended Learning Models https://www.blendedlearning.org/models/

4. Landscape Analysis of Personalized Learning in Massachusetts. MAPLE. LearnLaunch, 2017. Web. 14 March 2018.

5. Michael B. Horn, Heather Staker, Blended: Using Disruptive Innovation to Improve Schools. San Francisco: Jossey-Bass, 2014

3. Klimova, Blanka; Poulova, Petra, Personalized Learning Environment - A Case Study: Advanced Science Letters, Volume 22, Numbers 5-6, May 2016, pp. 1129-1132. 